\title{
ACCIONES CONTENCIOSAS: LA RUPTURA DE 1989
}

\author{
MÓNICA GORDILLO (IDH.CONICET-UNC) \\ Instituto de Humanidades. Unidad Ejecutora CONICET \\ Universidad Nacional de Córdoba \\ gordillo.monica@gmail.com
}

\section{Resumen:}

En este artículo tratamos de inscribir las acciones por demandas de alimentos ocurridas en 1989 y 1990 dentro de un marco de análisis que busca explicar los cambios en la movilización de las clases populares en relación con las transformaciones operadas en el sistema en su conjunto, reflexionando acerca del doble sentido de lo ocurrido: como continuidad de una particular politicidad que buscó expresarse en el espacio público pero, también, como una ruptura en los sentidos construidos y en el repertorio de la acción colectiva. Así, consideramos esas acciones entre las que los saqueos aparecen como una forma de violencia colectiva- no sólo como una reacción ante la situación de crisis terminal del gobierno de Raúl Alfonsín sino, también, como una acción política "contenciosa" que busca expresarse por canales diferentes de los de la política rutinaria convalidada en las elecciones generales del 14 de mayo de 1989.

\section{Palabras claves:}

Política Contenciosa - Acciones por Alimentos - Saqueos

\begin{abstract}
:
In this article we try to register the actions for food demands occurred in 1989 and 1990 within an analitical framework that seeks to explain the changes in popular classes's mobilization related to system's transformations as a whole, reflexing about the double meaning of what happened: as a continuity of a particular politicity that tried to express itself in the public space, but also, as a break in the senses and repertoires of collective action. We consider these actions -where looting appears as a form of collective violence- not only as a reaction to terminal crisis's situation of Raúl Alfonsín's government but, also, as a "contentious" politics that intended to express demands through different channels of routine policy, validated in general elections of May 14th 1989.
\end{abstract}

\section{Keywords:}

Contentious Politics - Actions for Food Demands - Lootings 


\title{
ACCIONES CONTENCIOSAS: LA RUPTURA DE 1989
}

\section{MÓNICA GORDILLO (IDH.CONICET-UNC)}

\author{
gordillo.monica@gmail.com
}

\section{Introducción:}

En mayo y julio de 1989, en el contexto de la primera hiperinflación vivida en el país, tuvieron lugar -también por primera vez en la historia argentina- acciones de protesta por alimentos y saqueos en varios barrios de las ciudades de Rosario, Córdoba y del conurbano bonaerense. Esas acciones, así como otras expresiones de la conflictividad social en ascenso que llevaron a establecer el estado de sitio el 30 de mayo, fueron decisivas para fundamentar la entrega anticipada del gobierno a Carlos Menem, candidato del Partido Justicialista (PJ) y triunfante en las elecciones nacionales del 14 de mayo.

Ahora bien, ¿cómo fueron explicadas esas acciones? Inmediatamente de ocurridas varias opiniones destacaron el carácter organizado de las mismas, aludiendo con ello no a la autoorganización de los participantes sino a la incidencia de redes clientelares del PJ que habrían intervenido para incidir en los resultados electorales, acentuar el clima de inestabilidad y desprestigio de la Unión Cívica Radical (UCR) en el gobierno y favorecer con ello la entrega anticipada del poder. Sin embargo esta hipótesis debiera ser revisada al menos ante dos constataciones: las elecciones tuvieron lugar antes de los saqueos por lo tanto esos hechos no pudieron incidir en el resultado electoral y, además, se repitieron una vez asumido el nuevo presidente, tanto en julio como en febrero de 1990; por otro lado, ha sido suficientemente documentada la falta de interés de Menem de asumir el gobierno antes de tiempo.

Esas explicaciones, que arraigaron rápidamente en el sentido común, tuvieron también resonancias en el ámbito académico donde, por ejemplo, Auyero ${ }^{1}$ sostuvo una argumentación similar en su libro sobre los saqueos del año 2001 en el conurbano bonaerense. Su explicación se inscribe en la propuesta de abordar relacionalmente la violencia colectiva tomando como referencia el planteo de Tilly $^{2}$, quien la considera siempre resultado de la interacción y coordinación entre personas y donde se adjudica un lugar destacado a los activistas o agentes de violencia. En ese sentido las "relaciones clandestinas"3 son importantes tanto en la generación de la violencia colectiva como en la vida partidaria. Esas relaciones conformarían el espacio de una "zona gris" donde las divisiones y límites entre los insurgentes, agentes del Estado (como la

1 Cf. Auyero, Javier, La zona gris. Violencia colectiva y política partidaria en la Argentina contemporánea, Buenos Aires, Siglo XXI, 2007.

2 Tilly, Charles, Violencia colectiva, Barcelona, Hacer, 2007, p. 3.

3 Auyero, Javier, La zona gris..., op. cit., p. 26. 
policía) y activistas de los partidos políticos se desdibujarían en cuanto a sus posiciones frente a la violencia, pudiendo aceptarla e incluso fomentarla, borrándose de ese modo los límites entre la política institucionalizada y no institucionalizada. ${ }^{4}$ Este análisis permitiría integrar la violencia colectiva "extraordinaria" -como sería el caso de los saqueos- en el estudio de la "normalidad" política. ${ }^{5}$

Más allá del uso clientelar que este planteo presupone, lo que destaca este autor es la necesidad de considerar redes cotidianas entre actores disímiles que se pondrían al servicio de acciones extraordinarias, por ejemplo en el contexto de 2001. Estas observaciones abren una pregunta: ¿es posible pensar en una explicación similar para las acciones de 1989?, ¿estaban ya para entonces constituidas redes de movilización que permitirían comprender lo ocurrido como resultado de la interacción y de cierta organización?

Desde otra perspectiva y sin centrarse específicamente en este tipo de acciones de violencia colectiva, Merklen ${ }^{6}$ ha destacado la conformación de una nueva politicidad y de un nuevo repertorio de confrontación entre las clases populares durante la década de 1980 que se caracterizaría por la movilización de base territorial, con la acción directa como elemento común más allá de los formatos diferentes utilizados. Según él, sus primeras expresiones remontarían a las ocupaciones ilegales de tierras en el sur del Gran Buenos Aires hacia 1981 donde, a su vez, habrían empezado a conformarse nuevos actores e instituciones pero manteniéndose también tradiciones que remitirían a un pasado de integración social que se encontraría en la base de las diversas demandas de reparación que la recuperación democrática debía atender. Lo que el autor intenta mostrar es el desarrollo de una politicidad ${ }^{7}$ que buscará adaptarse a los nuevos tiempos generando otros aliados y espacios frente al corrimiento de los canales de integración anteriores; politicidad que -según él- pasó inadvertida tanto para la mayoría de los actores políticos del momento como para los académicos que analizaron el período tendiendo a despegar los procesos políticos de lo que ocurría en la sociedad.

Como vemos, ambos autores destacan la necesidad de considerar las bases locales, informales, y los componentes específicos en el accionar político de los sectores populares. Sin embargo la diferencia entre los dos planteos estaría dada en el mayor énfasis puesto por el primero en agentes movilizadores en cierta forma externos a los sectores afectados, mientras que el segundo destacaría la constitución de una politicidad positiva donde las acciones aparecerían como respuesta -en cierta forma estratégica pero también moral- a lo percibido como "injusticia" 8 frente a derechos conculcados; más allá de que no se formulen en esos términos y que también se pongan en juego redes clandestinas para sostener la acción, como parte de una politicidad constituida previamente. En este sentido, el que se hubieran utilizado redes barriales del PJ no mostraría necesariamente un uso "clientelar" de las mismas; en todo caso hablaría de estructuras movilizadoras entre los sectores populares que estarían dando cuenta de nuevas realidades, de canales de movilización diferentes de los más tradicionales centrados en los sindicatos y, tal vez, de la conformación de nuevos repertorios y demandas cuyas trayectorias hay que considerar.

\footnotetext{
4 Auyero, Javier, La zona gris..., op. cit., p. 42.

5 Auyero, Javier, La zona gris..., op. cit., p. 54.

6 Cf. Merklen, Denis, Pobres ciudadanos. Las clases populares en la era democrática (Argentina, 1983-2003), Buenos Aires, Gorla, 2005.

7 Merklen utiliza este término para designar la "condición política" de las personas, englobando en este concepto el conjunto de sus prácticas, su socialización y su cultura política. Cf. Merklen, Denis, Pobres ciudadanos..., op. cit., p. 24.

8 En el sentido planteado por Gamson que la considera como una hot cognition construida socialmente activando marcos de sentido que avivan la acción. Cf. Gamson, William, "Constructing social protest", en Jonsthon H. y Klandermans B., Social movements and culture, University of Minnesotta Press, 1995, p. 90.
} 
Por otra parte es necesario señalar que el análisis de Auyero concentra su atención en una de las condiciones para la existencia de la violencia colectiva -los activistas o agentes promotores- sin atender otros componentes que el mismo Tilly enfatiza como es el de considerar el tipo de violencia colectiva en relación con las características del régimen político. Según su planteo, los regímenes democráticos de capacidad baja serían más propicios para acciones violentas ya que sin medios gubernamentales para defender derechos, hacer cumplir las obligaciones y contener conflictos, una diversidad de actores se enfrascan en tratar de lograr sus intereses por sus propios medios ${ }^{9}$. Esto abre la pregunta acerca de las características de los gobiernos donde esas acciones tuvieron lugar. Otro elemento importante es también la activación de las divisorias entre un nosotros afectado y un ellos causante de la afección, donde la tarea de los emprendedores políticos es fundamental en las actividades de conexión, coordinación y representación, ${ }^{10}$ pero sobre un terreno donde previamente se ha generado la percepción de negociaciones rotas y se ha activado la representación de injusticia.

Siguiendo ese planteo, en este artículo trataremos entonces de inscribir las acciones y el tipo de demandas sostenidas dentro de un marco de análisis más general que busque explicar los cambios producidos en la movilización de las clases populares en relación con las profundas transformaciones operadas en el modelo de integración social en el que se habían consolidado las identidades populares en el pasado; reflexionando a su vez acerca del doble sentido de lo ocurrido: como continuidad de una particular politicidad que buscó expresarse en el espacio público pero, también, como la instauración de una ruptura en los sentidos construidos y en el repertorio de la acción colectiva.

En relación con lo anterior, consideraremos las acciones por demanda de alimentos -entre las que los saqueos aparecen como una forma de acción directa que en algunos casos se convierte en violencia colectiva- no sólo como una reacción ante la situación de crisis terminal del gobierno de Raúl Alfonsín, como un grito o pura negatividad sino, también, como una acción política "contenciosa" " que busca expresarse en las calles y en los barrios, es decir por canales diferentes de los de la política rutinaria convalidada en las elecciones generales del 14 de mayo, un particular ejercicio ciudadano frente a los considerados como derechos vulnerados, que justificaba demandar por su restauración.

De este modo, siguiendo a Tilly, entendemos como política contenciosa a una forma de la acción política caracterizada por:

"las interacciones públicas, colectivas, episódicas entre promotores de demandas cuando a)

\footnotetext{
9 Tilly, Charles, Violencia colectiva, op. cit., p. 48.

${ }^{10}$ Tilly, Charles, Violencia colectiva, op. cit., p. 76.

11 Ésta aparece como una traducción del concepto contentious politics tal como es expresado en el libro de Aminzade, Ronald; Goldstone, Jack; Mc Adam, Doug; Perry, Elizabeth; Sewell Jr., William; Tarrow, Sidney y Tilly, Charles, Silence and voice in the study of contentious politics. New York, Cambridge University Press, 2001, para diferenciarlo de "contienda política" (political contention), tal como se usa en la versión castellana de la obra de Mc Adam, Doug; Tarrow, Sidney y Tilly, Charles, Dinámica de la contienda política, Barcelona, Hacer, 2001. En la traducción al castellano de Dynamics of contention, New York, Cambridge University Press, 2001, se aclara que se prefirió cambiar el término inicial de "contestación" o contestatario por el de contienda, que hace referencia a una lucha o enfrentamiento abierto entre actores, agregándosele el calificativo de "política" para dar cuenta más acabada del contenido del libro; es decir que éste no trataba de cualquier contienda sino de una que implicaba de alguna manera una definición del orden público o al poder del Estado. Sin embargo consideramos que, tal como se plantea en el libro de Aminzade et al, aparecido con posterioridad, y donde se hace referencia no a "contention" sino a "contentious politics" como una forma o modalidad particular que puede asumir la acción política, tal vez sería más conveniente mantener la traducción más literal de "política contenciosa", que proponemos, dado que en castellano el término "contencioso" hace referencia a contradecir lo que otros afirman, aplicándose a las materias sobre las que se litiga y al procedimiento para litigar.
} 
al menos alguna de las interacciones adopta formas no institucionalizadas, b) al menos un gobierno es el demandante, objeto de las demandas o una parte de los reclamos y c) los reclamos afectarían, si se concretan, los intereses de al menos uno de los demandantes". ${ }^{12}$

Los autores señalan que a veces se desarrolla dentro de las formas prescriptas de la participación política, en algunas ocasiones bajo modalidades toleradas y, en otras, bajo formas prohibidas por el régimen, caracterizándose por ser un tipo de acción política más episódica que rutinaria, poco institucionalizada, pero cuya comprensión requiere considerar el sistema en su conjunto. De allí que, justamente, comencemos caracterizando a continuación los rasgos principales del funcionamiento de ese sistema en el período estudiado.

\section{La exclusión como ruptura y la oportunidad política para la violencia}

La derrota en las elecciones parlamentarias de 1987 llevó al presidente Alfonsín a buscar la cooperación sectorial que consideraba necesaria para culminar su mandato. Para ello profundizó las concesiones a los sectores corporativos lo que acentuó la crisis fiscal que se puso en evidencia ya a comienzos de 1988. Para entonces se decidió un nuevo paquete impositivo, una devaluación y un congelamiento de precios, acompañado de una actualización de las tarifas públicas que superaron el aumento del 12\% en los salarios acordados con la CGT; a su vez la presión sobre el tipo de cambio y la sangría de reservas buscaron frenarse desdoblando el mercado cambiario con un dólar financiero que flotaría libremente. Esas medidas se completaron con el cierre de los redescuentos a bancos provinciales, por lo que varias provincias tuvieron problemas para pagar sueldos, en especial las controladas por gobiernos peronistas como La Rioja, Tucumán, Salta, Catamarca y Chaco; policías, empleados administrativos y docentes ocuparon las capitales exigiendo pagos de haberes o "aunque más no fuera comida"13. A mediados de 1988 los precios internacionales que habían caído se recuperaron en un 30\%; sin embargo tuvieron un efecto negativo porque impactaron en los precios internos sin que el fisco sacara ventaja porque se había comprometido a no incrementar las retenciones a las exportaciones. El dólar comercial subvaluado tampoco logró frenar el alza local de los alimentos que se convirtió en la primera mitad de 1988 en el principal motor de la inflación. ${ }^{14}$

A su vez, el discurso del gobierno se acercaba cada vez más a la orientación propuesta por Eduardo Angeloz, candidato radical a la presidencia, quien sostenía la necesidad de reformar el Estado y avanzar en políticas neoliberales. A medida que fue haciéndose más inminente el triunfo de Memen, la presión externa sobre la deuda se tornó asfixiante. El 6 de febrero de 1989 el Ministro de Economía anunció que ya no sacrificaría reservas y que todas las exportaciones se pagarían al dólar regulado, lo que hizo saltar la tasación del libre un 45\% y las reservas siguieron cayendo debido a la suspensión total de las liquidaciones por parte de los exportadores. Para convencerlos, el gobierno permitió que la tasa de los depósitos subiera al 30\% mensual. A fines de marzo el dólar alcanzó un valor $177 \%$ superior al de enero, en abril había aumentado ya $400 \%$, la inflación escaló un $17 \%$ en marzo y $33,4 \%$ en abril. ${ }^{15}$ En ese marco de alta inflación, las divisiones dentro del propio partido gobernante acerca de la orientación a seguir -entre los funcionarios y el candidato a presidente-, debilitaron aún más la capacidad del gobierno para manejar la crisis. Angeloz presionó para el alejamiento de Sourrouille, quien estaba decidido a

12 de Aminzade, Ronald et al., Silence and voice..., op. cit., p. 7.

${ }_{13}$ Novaro, Marcos, Argentina en el fin de siglo. Democracia, mercado y nación, Buenos Aires, Paidós, 2009, p. 277.

14 Novaro, Marcos, Argentina en el fin de siglo..., op. cit., p. 278.

15 Novaro, Marcos, Argentina en el fin de siglo..., op. cit., p. 302. 
endurecer la política monetaria y fue reemplazado por Pugliese, quien buscó tentar a los exportadores con un tipo de cambio mixto que los beneficiaba pero fue inútil, no liquidaron. Se elevó la tasa de interés al 100\% mensual a fines de abril para absorber pesos. La desorientación en el gobierno era total, Angeloz impuso su criterio contrario a la regulación de los mercados convenciendo al gobierno de que liberaran el tipo de cambio en abril, a un mes de las elecciones. A pesar del congelamiento impuesto en mayo a bienes de consumo masivo, la inflación fue del $104 \%$ y los ingresos públicos cubrían apenas el 25\% de los gastos. En junio los precios subirían $132 \%$ y $209 \%$ en julio. Totalizaba un alza de $934 \%$ desde enero mientras que el dólar había trepado un $2.426 \% .{ }^{16}$

El país se encontraba ante una hiperinflación. Esta requirió de la combinación de una multiplicidad de acciones y actores. Según Novaro, más que resultado de una conspiración política, la hiperinflación mostró ciertas ausencias; en primer lugar la de un Estado con capacidades mínimas para cobrar impuestos, dominar la especulación privada, la fuga de capitales y preservar así el valor de la moneda y, asociadas a ellas, la de un vértice político con recursos para crear certidumbre y administrar la transferencia del poder a su sucesor. ${ }^{17}$ Es decir, se trataba de un gobierno democrático con una muy baja capacidad para actuar y, por lo tanto, proclive a generar condiciones para acciones violentas.

Pero lo determinante para nuestro tema es destacar las consecuencias de esa incapacidad política sobre los indicadores sociales. En 1989 el desempleo se había elevado al 8\%, saltando el ritmo de crecimiento anual del 2,8\% sostenido durante los años previos, pero la pobreza que en 1974 había sido del 5,1\% y trepado al 26,3\% en 1983 para caer con la aplicación del Plan Austral al 16,1\%, llegaba en 1988 al 33,6\% y en 1989 tocaba el 42,1\%. ${ }^{18}$ Ese era entonces el marco en el que se generalizó la exclusión hacia 1989 y en el que tuvieron lugar las elecciones presidenciales del 14 de mayo:

"Una catástrofe se abate sobre el país, no se debe ni a un terremoto ni a una gran inundación o ciclón, ni a una guerra [...] sin embargo sus efectos son más devastadores que la peor calamidad natural. [...] Lo que está ocurriendo es la crisis más grave de un país saqueado durante décadas, que pagó sólo durante el gobierno de Alfonsín 15.000 millones de dólares a los usureros de la deuda externa; donde los gobiernos facilitaron a los grandes oligarcas la fuga de capitales, en total 40.000 millones de dólares según el Banco Mundial. [...] En pocas semanas el deterioro es inmenso, si dos millones de familias ya se acostaban sin cenar, ahora son tres millones y pronto serán cuatro millones. Cierran en quiebra miles de pequeños comercios y los cuentapropistas ya no consiguen ni el rebusque de la changa. [...] Pero la locura hiperinflacionaria está lejos de haber llegado a su fin destructivo. Es muy diferente a la inflación normal e incluso a la muy alta inflación que sufrimos desde 1975. [...] Según un informe interno de la UIA sobre 300 empresas que consultaron serán suspendidos en promedio el 45\% de los trabajadores y piensan despedir al 18\%. El país se llena de ollas populares y comedores para los pobres. Esta catástrofe ya está hambreando y destruyendo a centenares de miles de familias y será mucho peor en las próximas semanas o meses $[\ldots]^{, 19}$

\footnotetext{
${ }^{16}$ Novaro, Marcos, Argentina en el fin de siglo..., op. cit., p. 306.

${ }_{17}$ Novaro, Marcos, Argentina en el fin de siglo..., op. cit., p. 309.

${ }_{18}$ Novaro, Marcos, Argentina en el fin de siglo..., op. cit., p. 317.

19 Solidaridad Socialista.Tribuna independiente del pensamiento socialista, A. VII N² 285, 14/6/1989, p. 6.
} 


\section{Por el derecho a comer}

Más de cien vecinas amas de casa de los barrios cordobeses de Villa Páez y Alberdi se congregaron el 22 de mayo de 1989 en una plazoleta y, al son de las cacerolas, protestaron contra la suba de precios de los alimentos. Dos días después, en un accionar simultáneo y organizado, distintos grupos de mujeres y niños de diferentes villas de emergencia realizaron saqueos a supermercados. ${ }^{20}$

El 29 de mayo, al cumplirse veinte años de la paradigmática movilización popular en Córdoba contra el gobierno dictatorial de Onganía, conocida como "Cordobazo", tuvo lugar en Rosario otro estallido muy diferente de aquél, una ola de saqueos contra supermercados y comercios reclamando alimentos y productos de la canasta básica con el resultado de dos muertos. Al día siguiente el gobernador de Santa Fe, Víctor F. Reviglio, ordenó reprimir contándose seis muertos más. Mientras tanto similares acciones se desparramaban por decenas de supermercados del conurbano bonaerense produciendo enfrentamientos con la policía con el saldo trágico de ocho muertos y cientos de heridos. ${ }^{21}$ Ese día el gobierno dispuso el estado de sitio. Los saqueos continuaron el día 31 en doce localidades del conurbano bonaerense donde un comerciante y sus custodios abatieron a dos saqueadores, sumándose tres muertos más entre ellos un niño de 9 años. También en Tucumán murió un joven de 19 años aplastado por bolsas de azúcar, quedando veintiún manifestantes detenidos a disposición del PEN. ${ }^{22}$ Ese día también en Córdoba se registraron distintas escaramuzas e intentos de saqueos que fueron evitados por la policía, registrándose varios detenidos. ${ }^{23}$ En menos de una semana se habían producido 19 muertos.

Pero las acciones para proveerse de alimentos no terminaron ahí sino que se utilizaron otros recursos. Por ejemplo en La Matanza se sucedieron asambleas barriales, cortes de ruta y movilizaciones. En San Alberto se instaló una olla popular para paliar el hambre de los niños, varios comerciantes cerraron sus locales y se sumaron a la protesta. En Ciudad Evita, ante la falta de provisiones de partidas oficiales para los comedores escolares, por estar suspendidas, se levantaron carteles que decían: "si no saben gobernar que se vayan", "mi papá no tiene trabajo y tenemos hambre; "Que se vaya este gobierno". En Rafael Castillo seiscientos vecinos marcharon acompañados por el cura del barrio a la plaza central, la iglesia quedó como centro coordinador, se eligieron comisiones para ir a las fábricas planteando la huelga general y muchos pidieron la renuncia del gobierno. ${ }^{24}$

En la ciudad de Santa Fe, como en otras provincias, se trató de aplacar el descontento proveyendo cuarenta y cinco toneladas de alimentos a través de las parroquias y cuarenta mil litros de leche en los institutos dependientes de la Secretaría de Promoción Comunitaria. Sin embargo el malestar aumentó cuando el 6 de junio noventa mil trabajadores del Estado entraron en huelga exigiendo que se les pagaran los salarios, unificándose en el paro todos los estatales, municipales, docentes y judiciales a través de una coordinadora que se comprometió a actuar conjuntamente en caso de cualquier represalia. ${ }^{25}$ Según datos oficiales, las villas de emergencia

\footnotetext{
${ }^{20}$ Diario La Voz del Interior, Córdoba, 22/5/1989, p. 9 A y 25/5/1989, p. 10 A.

${ }^{21}$ Diario La Voz del Interior, Córdoba, 30/5/1989, p. 1 y 31/5/1989, p. 12.

22 Diario La Voz. del Interior, Córdoba, 1/6/1989, p. 10 A y 2/6/1989, p. 10 A.

23 Diario La Voz del Interior, Córdoba, 1/6/1989, p. 10 A.

24 Solidaridad Socialista. Tribuna independiente del pensamiento socialista, A. VII N² 283, 31/5/1989, p. 4.

25 Solidaridad Socialista. Tribuna independiente del pensamiento socialista, A. VII N² 285, 14/6/1989, p. 8. La revista muestra además indicadores sociales de esa situación: “[...] La catástrofe que vivimos tiene cifras elocuentes. El consumo popular cayó sólo en estos días en un 70\%. Las ventas en los almacenes se redujeron un 40\%, la carne se vende un $30 \%$ menos, los fiambres un 45\% y los artículos del hogar bajaron un $75 \%$ sus ventas. El hambre ha hecho que surjan miles de ollas populares, junto al hambre otra peste hace estragos, hay 1.200.000 trabajadores suspendidos en
} 
sólo en Rosario albergaban a más de 100.000 personas. A las huelgas con ollas populares de los municipales de la ciudad de Santa Fe, que para fines de junio continuaban, se sumaron el 28 los carniceros rosarinos quienes decidieron no abrir sus negocios en protesta por el precio de la carne. Otro tanto hizo la Cámara de Supermercados y Almacenes, argumentando su temor ante otro estallido mientras crecía el malestar policial por los bajos salarios y los rumores de autoacuartelamiento. Ese marco produjo a su vez la renuncia de los intendentes de Rosario y Santa Fe, éste último acusado de corrupción y malversación de fondos. ${ }^{26}$

El anuncio de la entrega anticipada del gobierno por parte de Alfonsín, realizada a mediados de junio, pareció frenar momentáneamente otras acciones. Sin embargo éstas se reeditaron apenas asumido Menem el 8 de julio. Ese mismo día en la zona sur de la ciudad de Córdoba, en barrio Parque Capital, un grupo de vecinos detuvo un camión que transportaba bolsones de harina llevándose casi toda la carga. ${ }^{27}$ En los días siguientes y hasta el 13, tuvieron lugar intentos de saqueo de supermercados Cordiez en una zona colindante entre los barrios Matienzo y Ameghino Sur y en Av. Fuerza Aérea; también en un Supercoop de Av. Colón y en barrio Pueyrredón, y otros negocios en San Salvador. El hecho de mayor trascendencia fue la detención de veintiún "saqueadores" del supermercado "Colinas" en barrio Colinas de Vélez Sarsfield donde predominaban hombres y mujeres muy jóvenes, ninguno de más de treinta años, ubicándoselos como vecinos de Parque Capital y de Costa de la Cañada. ${ }^{28}$

Nuevamente otro hecho trágico se registró en San Miguel de Tucumán al ser asesinado Luis Machado, de 19 años, el 11 de julio por el disparo de la dueña de un negocio que intentaba ser saqueado. Desde el día anterior se habían producido este tipo de acciones en varios negocios, llevados a cabo siempre en grupos. En la ciudad de Resistencia ciento cincuenta personas se concentraron frente a casa TIA solicitando mercaderías, a lo que los directivos accedieron como una "contribución", pero pidieron que los manifestantes se retiraran y formaran una comisión con un representante por barrio. ${ }^{29}$ Es de destacar que una de las razones posibles de haberse elegido este blanco en particular haya sido que esa casa no respetó los precios máximos establecidos por el gobierno, por ejemplo en un artículo básico como la leche en polvo fijado en 960 australes y que se vendía a $1640 .^{30}$

Para comprender esas acciones es necesario tener en cuenta algunos datos. En lo que refiere al conurbano bonaerense se indicaba que 3.000.000 de personas padecían hambre, ascendiendo a 8.000.000 en todo el país. Sólo en Lomas de Zamora se consignó la existencia de 163 centros de abastecimiento para alimentar a 300.000 personas, lo que representaba casi la mitad de toda la población del partido. ${ }^{31}$ En Moreno funcionaban 264 ollas populares en las que comían 65.000 personas. ${ }^{32}$

el país. Sólo en Capital Federal y Gran Buenos Aires 69 empresas metalúrgicas despidieron, suspendieron o adeudan salarios en mayo [...]", p. 12.

26 Solidaridad Socialista. Tribuna independiente del pensamiento socialista, A. VII N²87, 27/6/1989, p. 3.

${ }^{27}$ Diario La Voz del Interior. Córdoba, 9/7/1989, p. 12 A.

${ }^{28}$ Diario La Voz del Interior. Córdoba, 11/7/1989, p.10 A; 13/7/1989, p. 10 A y 14/7/1989, p. 10 A. Este último diario indica los nombres de todos los detenidos.

${ }^{29}$ Diario Página/12, Buenos Aires, 11/7/1989, p. 10;12/7/1989, p. 9.

30 Diario Página/12, Buenos Aires, 14/7/1989, p. 4.

31 Solidaridad Socialista. Tribuna independiente del pensamiento socialista, A. VII N 286, 20/6/1989, p. 5.

32 Solidaridad Socialista. Tribuna independiente del pensamiento socialista, A. VII N 288 4/7/1989. 


\section{Vecinos organizados, algunas experiencias}

Hasta aquí hemos efectuado una descripción que relaciona lo ocurrido con la situación de extrema vulnerabilidad padecida por gran parte de los sectores populares. Sin embargo consideramos que esto no basta para explicar acciones colectivas que, en muchos casos, culminaron en violencia. Siguiendo la línea planteada por Merklen y también por Tilly, nos parece necesario indagar algunos antecedentes de organización en torno a las nuevas condiciones generadas a partir de la restauración democrática. En efecto, las dificultades del gobierno para revertir la pobreza con políticas activas lo llevó a la temprana implementación del Programa Alimentario Nacional (PAN), que fue complementado con algunas iniciativas locales. Como ejemplos de ello pueden citarse los desarrollados por los municipios de Moreno y Lomas de Zamora en el conurbano bonaerense, así como los planes de "asistencia participativa" impulsados por el gobernador Cafiero en Buenos Aires desde 1987. La puesta en marcha de los mismos en muchos casos fomentó la organización de base territorial promoviendo dispositivos democráticos (directos o indirectos) para la toma de decisiones que habrían a su vez operado como espacios de interacción para la construcción de politicidades y, también, como estructuras movilizadoras para instalar demandas que se fueron configurando como derechos a resguardar. En ese proceso, la misma práctica de demandar se fue construyendo como un derecho. Merklen ha señalado que en ocasiones se generaron también mecanismos de representación más formales como la elección de dirigentes barriales $\mathrm{o}$, incluso, la conformación de cuerpos de delegados construyéndose así espacios públicos locales con reglas de funcionamiento específicas.

En ese sentido hemos encontrado numerosas evidencias de autoorganización barrial para enfrentar los innumerables problemas generados ante la incapacidad del gobierno democrático de revertir el empobrecimiento. Las experiencias refieren, por ejemplo, a comisiones de vecinos que se encargan de rondas nocturnas de patrullajes y sistemas de alarmas ante robos a través del uso de silbatos; coordinadoras de barrios que realizan acciones y petitorios contra los aumentos de tarifas públicas; comisiones para solicitar ante las autoridades por situaciones de anegamiento, malas condiciones de las calles, entre muchas otras cuestiones. ${ }^{33}$ Creemos que, ante la disminución de la asistencia o directamente la suspensión de la provisión de alimentos -tal como se venía haciendo a través de los distintos planes- esas mismas estructuras informales habrían intervenido en la motorización ahora de acciones directas para la provisión de los mismos. Parece evidente que las mismas respondieron a una organización que no se limitó a las acciones puntuales sino que buscó sostenerlas y procesarlas en el tiempo dotándolas de un sentido público construido en la interacción que pretendía trascender la demanda para avanzar sobre sus causas.

En este sentido resulta muy oportuna la observación de Nardacchione con respecto a la constitución del sentido de las acciones colectivas. Señala que, en general, las demandas siguen un recorrido que va del rechazo radical a la formulación de un proto-discurso demandante. En la primera etapa el ¡No! radical permite unificar a todos los que protestan alrededor de una consigna sencilla y genérica a la vez; se trata de agrupar a todas las víctimas que sufren la misma afectación. Esta etapa todavía podría considerarse la de la reacción colectiva, donde se está simplemente consolidando una víctima común. Es el momento de la definición de un antagonista donde lo que predomina todavía es la particularidad de la demanda. Si la misma se mantiene en el tiempo es posible que empiece a articularse un sentido público donde se busca ampliar la interacción, no ya sólo hacia el oponente sino también hacia un público que se intenta atraer, para lo que la demanda empieza a perder la particularidad inicial y formularse en términos de derechos que

33 Solidaridad Socialista. Tribuna independiente del pensamiento socialista, A. VI No 240, 28/6/1988, p. 6 y A. VI $\mathrm{N}^{\circ} 248$, 23/8/1988, p. 9, experiencias que se repiten en otros números de la revista. 
pueden implicar a todos, trascendiendo al colectivo o colectivos que la instalaron. Sin embargo, como ha señalado también este autor, esta tarea de formulación de la demanda puede tener dos derivaciones: una diferenciadora, que tiende a expresar más específicamente los reclamos de cada sector que participa de la protesta, u otra articuladora o integradora que busca criterios generales que unifiquen los reclamos particulares. ${ }^{34}$

Esa intención de trascender la inmediatez del reclamo y de avanzar sobre las causas del mismo, llevó a que muchas de las acciones de pedido de alimentos y organización de ollas populares fueran seguidas por la elaboración de censos de desocupados por parte de sus organizadores para exigir trabajo al gobierno; otras se continuaron con petitorios para frenar los despidos o suspensiones en fábricas aledañas, con proyectos de construcción de viviendas populares que a la vez generarían fuentes de trabajo, entre otros. ${ }^{35}$ Incluso se intentaron perfeccionar y hacer más eficientes los mecanismos de distribución ante la escasez:

"Quien manejaba la olla de lunes a viernes era la gente de la parroquia que los vecinos ayudamos a levantar. Pero no permitían que miráramos si sobraba o faltaba algo de lo que nosotros mismos habíamos conseguido. Entonces nos pusimos de acuerdo con la gente y formamos una comisión para que, de ahora en más, tengamos derecho a controlar todo lo que entra y sale. El otro problema era que las catequistas no tenían actividad el fin de semana. Nosotros nos preguntamos si el padre no come esos días. Por eso un vecino nos dejó usar su patio, otro consiguió las ollas, cada uno trajo lo que pudo para engordar el guiso ya que lo que da la municipalidad no alcanza y así pensamos comer este fin de semana." 36

Otro ejemplo de coordinación de las necesidades fue el llevado a cabo en General Sarmiento donde representantes de cuarenta ollas se presentaron ante la intendencia para exigir terminar con el reparto de víveres a través de personeros de la municipalidad y tomar en sus manos el control y distribución de los alimentos. El intendente debió ceder y entregarles la comida, a su vez esa coordinación elaboró un petitorio pidiendo trabajo para los desocupados. ${ }^{37}$

Mientras tanto también otros actores se posicionaron sobre la crítica situación que se vivía y acerca de la legitimidad de la demanda de alimentos. En Córdoba, por ejemplo, alrededor de ciento cincuenta delegados y activistas concurrieron a mediados de julio a la primera reunión para conformar la "Coordinadora de Delegados y Activistas de los gremios estatales". Entre los principales puntos votados se encontraba el de exigir el control de precios y la aplicación de la Ley 20.650 con la participación y control efectivo por parte de los trabajadores, la creación de un fondo de huelga y la implementación de ollas populares en todas las dependencias, exigiendo a su vez la declaración de la emergencia sanitaria y educativa en la provincia. ${ }^{38}$

Ahora bien, ¿'se produjeron cambios en relación a cómo enfrentar el problema de la pobreza y la desocupación con la asunción de Menem? Las primeras medidas adoptadas mostraron que, por el contrario, la orientación del gobierno no sólo no tomaba esto como prioridad sino que, además, tendería a profundizarlas sumando a importantes sindicatos afectados por las políticas de ajuste

\footnotetext{
34 Nardacchione, Gabriel, "La paradoja de las protestas vecinales bajo el menemismo: ¿cómo generalizar la protesta defendiendo lo propio?”, en Schuster, F.; Naishtat F.; Nardacchione G. y Pereyra, S. (comps.) Tomar la palabra. Estudios sobre protesta social y acción colectiva en la Argentina contemporánea, Buenos Aires, Prometeo, 2005, pp. 193-216.

35 Solidaridad Socialista. Tribuna independiente del pensamiento socialista, A. VII N 288 4/7/1989, p. 8.

36 Solidaridad Socialista. Tribuna independiente del pensamiento socialista, A. VII N 286, 20/6/1989, p. 5.

37 Solidaridad Socialista. Tribuna independiente del pensamiento socialista, A. VII N 289 13/7/1989, p. 4.

38 Solidaridad Socialista. Tribuna independiente del pensamiento socialista, A. VII N 290 20/7/1989, p. 8.
} 
en la administración pública y por los primeros ensayos privatizadores, como los realizados en los ferrocarriles a partir del decreto 666/89 del $1^{\circ}$ de septiembre que establecía un plan de 180 días para reducir el financiamiento del Estado en ellos y que fue luego complementado con cuatro decretos dados en enero de 1990 que contemplaban un programa de racionalización operativa y administrativa que comprendía también la supresión de servicios. Esas medidas dieron lugar a una de las primeras acciones de protesta que debió enfrentar el gobierno de Menem. ${ }^{39}$

\section{Nuevas acciones por demandas de alimentos}

A fines del mes de febrero de 1990 se reprodujo el mapa de este tipo de protestas casi en los mismos centros donde habían tenido lugar el año anterior. Los saqueos comenzaron el 21 en Rosario donde también se asaltaron camiones e, incluso, algunos medios hablaron de la presencia de "francotiradores" en la madrugada y tarde. Frente a esos hechos actuaron fuerzas coordinadas de la Policía Federal, de Santa Fe, Gendarmería y Prefectura Naval deteniendo a veinte personas. Tanto el Ministro del Interior, Julio Mera Figueroa, como el gobernador Reviglio subestimaron los hechos destacando que no tenían la magnitud de lo ocurrido en mayo de 1989 y los adjudicaron a la incitación de grupos de izquierda. Sin embargo el relato de la prensa ofrece otra imagen ${ }^{40}$, la simple suma de los participantes consignados habla de cerca de trescientas personas participando en distintas acciones ese día a las que al día siguiente se sumaron ciento setenta más en otros hechos similares. ${ }^{41}$ El propio intendente, Héctor Cavallero, señaló que había en la ciudad 20.000 pobladores en el límite de la pobreza; al día siguiente 15.000 kilos de alimentos llegaron en avión desde el gobierno nacional que también ofreció bonos. ${ }^{42}$

Algunos relatos de los participantes de las acciones en Rosario permiten identificar su composición social, varios eran vecinos de la Villa Manuelita, muchos de ellos adjudicatarios de planes FONAVI, en su mayoría portuarios desocupados o con trabajo precario desde la huelga de 1987; otros se señalaban como vecinos de la Villa "Cerámica", quienes llevaron 200 kilos de carne ante la expresión absorta del dueño del local:

"Nunca en treinta años que hace que vivo aquí vi tanta hambre. Lo del año pasado no fue igual. Ahora hay desesperación. Se iban cargando carne y chorizos. No robaron el radiocasette ni la máquina de calcular, ni cuchillos, solamente comida."43

En Córdoba, durante los mismos días y con una difusión espacial similar a la del año anterior, se

\footnotetext{
39 Cf. Gordillo, Mónica, "Reforma del Estado y acciones colectivas: la huelga ferroviaria de 1991", en Entrepasados A. XIII N²6, 2004.

${ }^{40}$ El diario La Nación registró lo siguiente: "Cien personas intentaron tomar una granja y almacén sin poder concretarlo; cuarenta violentaron la persiana de un autoservicio y fueron repelidos a tiros por el propietario. A las 2.30 cincuenta personas hicieron una barricada en la autopista a Buenos Aires y detuvieron un camión que transportaba 15 toneladas de víveres para una guarnición militar local. Otras barricadas se levantaron en otras partes. La policía efectuó un operativo en barrio Las Flores donde fueron atacados a tiros. Las principales acciones se concentraron en la zona sur [...]", Diario La Nación, Buenos Aires, 22/2/1990, p. 8. Las acciones continuaron el día siguiente: "[...] dos comercios en zona norte fueron saqueados por cincuenta personas, detuvieron a doce [...] una carnicería fue despojada de 250 kilos de carne por veinte personas [...] cincuenta personas atacó en Bv. Oroño un camión que transportaba pollos, las fuerzas de seguridad dispersaron a los saqueadores", Diario La Nación, Buenos Aires, 23/2/1990, p. 10.

41 Diario La Nación, Buenos Aires, 24/2/1990 p. 5

42 Diario Página/12, Buenos Aires, 22/2/1990, p. 5. El carnicero al que le habían robado los 250 kilos de carne dijo: “esto es hambre, aunque me joda yo no reprimiría”, Diario Página/12, Buenos Aires, 23/2/1990, p. 5.

${ }^{43}$ Diario Página/12, Buenos Aires, 25/2/1990, pp. 12 y 13.
} 
registraron acciones de saqueo llevadas a cabo principalmente por mujeres y niños en barrio San Roque y Güemes el 20 de febrero, en el supermercado Cordiez y en el Supercoop de la ruta 20 así como en barrio San Lorenzo el 21; las acciones continuaron el 22, en general todas en la zona sur de la ciudad ${ }^{44}$, allí se detuvo a tres personas que se trasladaban en una pick up, al parecer instando al saqueo. ${ }^{45}$ El día 23 también se registraron saqueos puntuales en Guaymallén (Mendoza), en San Miguel de Tucumán y en José C. Paz y Gervasio Pavón en el gran Buenos Aires. ${ }^{46}$

Las respuestas a esas acciones fueron la entrega de comida por parte de las autoridades y, en el caso de la provincia de Santa Fe, el reparto de 27.000 bonos de 15.000 australes cada uno destinados a quienes figuraban en padrones oficiales confeccionados a tal fin; esto se reforzó con la distribución barrial a través del Movimiento Villero Rosarino de 15.000 toneladas de alimentos enviadas por el gobierno nacional. ${ }^{47}$

La distribución de la comida dio lugar también a distintas formas de organización, por ejemplo la creación de una "Comisión Coordinadora para luchar contra el hambre" en el partido de Tigre que núcleo a varios barrios de General Pacheco, se movilizó a la intendencia y consiguió la distribución de 17 toneladas de comida, unas 3000 raciones a ser entregadas por la misma Comisión en base a sus propias listas. Es de destacar que esa experiencia de autoorganización es señalada como un gran logro:

“[...] El movimiento por la comida crece día a día y otros barrios comienzan a organizarse. Hay 7000 anotados para recibir alimentos y las raciones no alcanzan para tantos. Se resuelve repartir lo que queda y hacer una gran movilización el jueves 15 a la intendencia. [...] Hemos logrado una conquista enorme. Hemos logrado empezar a tomar en nuestras manos el problema de la comida en Tigre. Tenemos la obligación de encausar este proceso y darle continuidad a la lucha uniendo los barrios porque nuestra fuerza está ahí, en la unidad, pero sepamos que el problema no termina en la intendencia porque el hambre se sufre en todo el país. Acá el problema es el gobierno de Menem. Por eso así como nos unimos aquí tenemos que unirnos con todos los que están luchando, como los docentes y los ferroviarios $[\ldots]$ ". 48

Experiencias similares de organización se dieron en barrios del partido de Merlo. Como parte de las acciones que trascendían la satisfacción inmediata de una necesidad, esos barrios votaron ir a la marcha "Por la vida y la libertad. Contra el hambre, la represión y la impunidad", convocada por los organismos de derechos humanos para el 16 de marzo a las 18 hs desde Corrientes y Cerrito hasta el Congreso, en Capital Federal, uniéndose a los docentes, estatales y demás sectores populares que luchaban contra los planes del gobierno. La consigna condensaba el rechazo a la política económica que -según ellos- traicionaba el discurso de campaña de Menem quien había prometido "salariazo" y "revolución productiva". También se rechazaba la intervención de las Fuerzas Armadas en la represión de las protestas -como se había evidenciado en los últimos acontecimientos- y los indultos a militares sublevados, dados en octubre de 1989, que abrieron los otorgados luego a los integrantes de las Juntas militares sentenciados en 1985. El documento central reclamaba aumento de salarios, congelamiento de precios, alquileres y tarifas, incremento

\footnotetext{
44 Diario Página/12, Buenos Aires, 21/2/1990, p. 8; Diario La Voz del Interior, Córdoba, 22/2/1990, p. 10 A; 23/2/1990 p. 1 A.

45 Diario La Voz del Interior, Córdoba, 23/2/1990, p. 8 A, aquí se indican los nombres, edades y dirección de las personas detenidas.

46 Diario La Nación, Buenos Aires, 24/2/1990, p. 5.

${ }^{47}$ Diario Página/12, Buenos Aires, 27/2/1990, p. 11.

48 Solidaridad Socialista. Tribuna independiente del pensamiento socialista, A. VIII Nº 322, 14/3/1990, pp. 6 y 8.
} 
de la asistencia social y de los presupuestos de salud y educación, así como el cese de los despidos y suspensiones. ${ }^{49}$

Sin embargo para entonces la situación era diferente a la del año anterior. No porque se hubieran modificado los indicadores sociales sino porque el nuevo gobierno había dado pasos decisivos para recuperar la capacidad estatal necesaria para imponer una nueva política. En efecto apenas asumido logró, en agosto de 1989, la aprobación de las leyes de Emergencia Económica y de Reforma del Estado que abrieron paso a las reformas estructurales de la década que se iniciaba; asimismo comenzó a operarse una rearticulación del campo político logrando sumar a la mayoría de las corporaciones económicas y sociales. Esto se puso en evidencia cuando, respondiendo a la movilización de marzo, se organizó la conocida como "Plaza del Sî" en abril, en apoyo al nuevo rumbo de la política económica. Por otra parte, la identidad peronista del nuevo gobierno, la consolidación del discurso de ajuste y de la opción privatizadora como generadora de empleo, dificultaba encontrar aliados influyentes en los sindicatos y en la misma CGT, reduciendo las oportunidades políticas para la acción. Ese paulatino fortalecimiento de las capacidades estatales se coronaría al año siguiente con el lanzamiento del plan de convertibilidad. Tendrían que pasar algunos años para que nuevamente los costos sociales desatendidos durante los primeros años de la reconstrucción democrática, y profundizados a partir de la política de Menem, volvieran a irrumpir en la escena pública bajo la forma de nuevos repertorios de acción disruptiva protagonizada por nuevos y viejos colectivos.

\section{Reflexiones finales}

A partir de este artículo me interesó reflexionar sobre el sentido de ruptura de las acciones por alimentos ocurridas entre 1989 y 1990, tanto en relación a las demandas que nunca antes habían sido instaladas en el espacio público, como en cuanto a los nuevos repertorios y marcos de referencia que las mismas abrirían. En efecto, 1989 aparecería como una transición entre dos momentos. Por un lado como el fin de la etapa abierta luego de 1983 donde todavía se intentaba la restauración del orden social previo, caracterizado por la integración social en torno al trabajo y por un Estado que expandía las redes de servicios de manera universal. Por otra parte, como el comienzo de la estabilización de un nuevo sentido con respecto a la cuestión social, que consideraría al empobrecimiento y al desempleo como problemas susceptibles de ser atendidos a través de la asistencia focalizada, como desfasajes inevitables del crecimiento económico esperado y prioritario.

Como vimos, las distintas experiencias organizativas señaladas combinan la demanda alimentaria con la de trabajo, todavía en las acciones de 1989 pareciera predominar este segundo sentido. Para 1990, ante el cambio de gobierno y la aparición de recursos paliativos como los bonos, pareciera que comienza a estabilizarse en el espacio público $-\mathrm{y}$ tal vez al interior de los propios sectores populares- el status o condición de pobres que deben ser objeto de atención focalizada; se consolida así la pobreza como dato irreversible pero, a la vez, resultante de las ineptitudes individuales para aprovechar las oportunidades del mercado, borrándose la relación de causalidad con las políticas aplicadas. De este modo, la relación de ese pobre con el Estado será a través de la asistencia y, particularmente, con los poderes locales. Esa situación comenzará a modificarse más adelante, hacia la segunda mitad de la década. La marcha convocada para el 16 de marzo de 1990 es un síntoma del intento de articulación de otros sentidos con relación a las causas de la

49 Diario La Voz del Interior, Córdoba, 17/3/1990, p. 1 A. 
situación vivida; sin embargo las oportunidades políticas no lo hicieron posible.

En cuanto a los formatos utilizados por las acciones de 1989 y 1990, que fueron de la petición de alimentos al saqueo y luego a la organización de la distribución, aunque requiere de mayor indagación aparecen indicios de la utilización de estructuras movilizadoras previas como parte de las politicidades que se fueron reconfigurando en los de 1980. Consideramos también que a comienzos de 1989 se habrían dado ciertas oportunidades políticas para el estallido a partir de la demanda alimentaria, al consolidarse una situación de injusticia que rompía los acuerdos implícitos en relación a un gobierno democrático que había asumido prometiendo que con la democracia "se comía, se educaba, se curaba". Por otra parte, la incapacidad gubernamental para asegurar la gobernabilidad y las divisiones existentes en el seno del mismo partido radical en la coyuntura electoral, actuaron como incentivos para las acciones. ¿Qué sentido tuvieron las de julio de 1989?, ¿fue un acto demostrativo ante el nuevo presidente, una advertencia sobre la gravedad de la situación social para que se la colocara como prioridad en la agenda pública?; ¿y las de febrero de 1990, un intento por enderezar el rumbo de las primeras medidas adoptadas? Sin duda debe haber habido un poco de todo eso, la intención también de continuar con un tipo de politicidad acostumbrada a demandar al Estado, que se amparaba en la representación de derechos. Sin embargo la característica de crisis extrema reflejada en la hiperinflación construyó también la representación acerca de la necesidad de restituir las capacidades del Estado en un sentido muy diferente al que había existido con anterioridad, ahora basado en una fuga hacia adelante que permitiera salir de la catástrofe bajo una especie de selección de los más aptos donde los menos capacitados o eficientes quedarían en el camino.

Hemos planteado también que ese tipo de acciones puede ser considerado como una forma de política contenciosa, es decir que no se trató sólo de reacciones irracionales ante coyunturas críticas sino, más bien, como una forma de acción política no rutinaria y disruptiva para confrontar con las autoridades y para inscribir en el espacio público demandas ciudadanas en términos de derechos. En ese sentido resultan sugerentes algunas expresiones de los manifestantes frente a la entrega de alimentos, considerando que no debían agradecer lo recibido porque era una obligación de las autoridades entregar lo que les correspondía para su subsistencia. Sin duda ello remite a un pasado de integración que pretendió infructuosamente ser restaurado con la recuperación democrática, como parte de las ciudadanías a restablecer tras la violenta interrupción del orden constitucional en 1976. 